\begin{tabular}{|c|c|}
\hline Title: & $\begin{array}{l}\text { Fault Tolerant Control by Asymmetric Operation of Double Three-Phase PMSMs with } \\
\text { Inter-Turn Faults }\end{array}$ \\
\hline Authors: & Simon Foitzik, Martin Doppelbauer \\
\hline Institute: & $\begin{array}{l}\text { Karlsruhe Institute of Technology (KIT) } \\
\text { Institute of Electrical Engineering (ETI) }\end{array}$ \\
\hline Type: & Conference Proceedings \\
\hline Published at: & $\begin{array}{l}2020 \text { International Conference on Electrical Machines (ICEM) } \\
\text { Publisher: IEEE } \\
\text { Year: } 2020 \\
\text { ISBN: } 978-1-72819-945-0 \\
\text { Pages: } 1342-1348\end{array}$ \\
\hline Hyperlinks: & https://ieeexplore.ieee.org/document/9270817 \\
\hline
\end{tabular}

(C) 2019 IEEE. Personal use of this material is permitted. Permission from IEEE must be obtained for all other uses, in any current or future media, including reprinting/republishing this material for advertising or promotional purposes, creating new collective works, for resale or redistribution to servers or lists, or reuse of any copyrighted component of this work in other works. 


\title{
Fault Tolerant Control by Asymmetric Operation of Double Three-Phase PMSMs with Inter-Turn Faults
}

\author{
Simon Foitzik, Martin Doppelbauer
}

\begin{abstract}
Inter-turn faults are most likely the initial stator winding fault in variable speed drive systems with Voltage Source Inverters. The machine must stay within its thermal requirements locally at the fault to prevent its propagation. In this paper, we present a fault tolerant control scheme for a double three-phase Permanent Magnet Synchronous Machine which minimizes the propagation of the fault by adapting the operating points of both systems independently. We estimate the generated heat by the inter-turn fault with a machine learning regression. If the estimated heat of the faulty system is greater than a definite value, the operating point of this system is adapted until the estimated heat is below the limit. The healthy system is used to compensate the torque reduction of the faulty system. We validated the concept of the control scheme with a Finite Element Analysis simulation. The presented double threephase machine can compensate $13.9 \mathrm{~W}$ at nominal torque, which is an improvement of $\mathbf{7 4 \%}$ compared to the equivalent single three-phase machine with the same heat limitation strategy. This heat reduction equals a temperature reduction of $111.2 \mathrm{~K}$ at fault locally.
\end{abstract}

Index Terms-double three-phase, fault tolerant control, inter-turn fault, machine learning, permanent magnet synchronous machine

\section{INTRODUCTION}

The reason for inter-turn faults in drive systems with Voltage Source Inverters (VSIs) is mainly the overvoltage caused by the fast switching semiconductors [1]. Also the thermal-, electrical-, ambient- and mechanical stresses cause a consistent degradation of the winding insulation.Of all motor failures, $37 \%$ are related to stator winding faults [2]. These electrical faults can be classified as short circuit and open circuit faults. Short circuit faults include inter-turn, phaseto-phase and phase-to-ground faults. Of all stator winding faults, $80 \%$ are caused initially by an inter-turn fault [3]. The propagation of an inter-turn fault is primarily determined by its local temperature [4]. This means the propagation can be minimized by limiting the temperature locally at the fault. With this information, we are able to develop a Fault Tolerant Control (FTC) scheme for Permanent Magnet Synchronous Machines (PMSM). FTC is especially needed for safety critical applications like all-electric aircraft to continue safe operation in case of a fault until the current

S. Foitzik is with the Institute of Electrical Engineering (ETI), Karlsruhe Institute of Technology (KIT), Kaiserstr. 12, 76131 Karlsruhe, Germany, (e-mail: simon.foitzik@kit.edu)

M. Doppelbauer is with the Institute of Electrical Engineering (ETI), Karlsruhe Institute of Technology (KIT), Kaiserstr. 12, 76131 Karlsruhe, Germany, (e-mail: martin.doppelbauer@kit.edu) load cycle is completed. There is one approach to prevent the propagation of an inter-turn fault by downregulation of the power, presented in [5]. The authors limit the current in the shorted turns to the nominal current but they do not further investigate the actual generated heat by the fault. In [6], the authors present a mitigation approach for interturn faults, albeit limited to PMSMs with negligible mutual inductance. They also do not consider the generated heat by the fault. In [7], we present a novel FTC scheme for threephase PMSMs which prevents the propagation by estimating and reducing the generated heat by the fault at constant speed. We estimate the generated heat of the inter-turn fault with a machine learning approach and adapt the dq-currents to limit the generated heat. Multiphase machines inherently feature an increased level of fault tolerance compared to conventional three-phase machines [8].For that matter, six-phase machines in general are practical to use because they can be fed by two conventional three-phase inverters. Therefore, we present in this paper a FTC scheme for double three-phase PMSMs. We use an independent control of the two threephase systems to increase the fault tolerant capabilities. The proposed control scheme uses the healthy machine part to compensate the downregulation of the faulty machine part. With this approach, we can compensate inter-turn faults significantly more effectively in double three-phase machines than with equivalent single three-phase machines.

\section{MACHINE ANALYSiS}

We focus on PMSMs due to their high power density and efficiency. There exist different approaches for the winding design of six-phase machines. One popular approach presented in [9] is called duplex winding and divides the sixphases into two three-phase systems, which are shifted by 30 electrical degrees. In [10], we present an analytical model to simulate duplex machines with inter-turn faults. The model emphasises the strong mutual coupling between both threephase systems, which prevents a beneficial independent control of the two three-phase systems during a fault. Therefore, we focus in this paper on a double three-phase machine with a minimum mutual coupling to be able to operate the two systems independently. The minimum coupling is achieved if every pole pair in the stator winding is fed by a single threephase inverter. With this approach, a three-phase electrical machine with $p$ pole pairs can be fed by the same amount of independent three-phase VSIs. 


\section{A. FEA Model}

One simple approach to analyse this winding design is to use two analytical three-phase PMSM models and neglect the mutual coupling among the two systems. This leads to simulation results for the overall machine torque with good accordance compared with Finite Element Analysis (FEA) simulations. However, the harmonic content of the phase voltages and fault current differs significantly compared to the FEA simulations, due to the neglected mutual coupling. Therefore, we focus on FEA simulations of the machine since the harmonic content is essential to estimate the severity of the inter-turn fault. We use the software Altair Flux ${ }^{\mathrm{TM}}$ for the 2D-FEA. The cross section of the analysed machine is shown in Fig. 1. The first three-phase system is located in the upper half of the stator and the second one in the lower half. All dq1 indices refer to the rotating reference frame of the first system and all dq2 indices refer to the second one, respectively. Each three-phase system consists of three distributed, symmetric and full-pitched phases. In contrast to most analytical models, the FEA model takes the nonlinear magnetic circuit, space harmonics and the mutual coupling among the two systems into account. This is why the FEA model is precise enough and suitable to parametrize the FTC scheme for the subsequent operation on the test bench. The machine parameters are summarized in Table I. The equivalent single three-phase machine is obtained by connecting both systems in series or parallel, which yields $i_{\mathrm{d} 1}=i_{\mathrm{d} 2}$ and $i_{\mathrm{q} 1}=i_{\mathrm{q} 2}$.

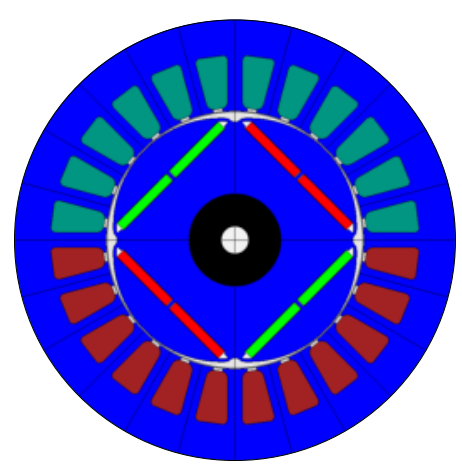

Fig. 1. Cross section of the analysed double three-phase PMSM with the first system in the upper part and the second system in the lower part.

TABLE I

MACHINE PARAMETERS

\begin{tabular}{lr}
\hline PMSM & values \\
\hline self-inductance $L_{\mathrm{d} 1,2}$ & $1.4 \mathrm{mH}$ \\
self-inductance $L_{\mathrm{q} 1,2}$ & $2.6 \mathrm{mH}$ \\
permanent magnet flux linkage $\psi_{\mathrm{PM} 1,2}$ & $82.8 \mathrm{mV} \mathrm{s}$ \\
maximum current $i_{\max }$ & $20 \mathrm{~A}$ \\
\hline nominal operating point & values \\
\hline nominal current $i_{\mathrm{d} 1,2} / i_{\mathrm{q} 1,2}$ & $-4 \mathrm{~A} / 14.3 \mathrm{~A}$ \\
nominal voltage $v_{\mathrm{d} 1,2} / v_{\mathrm{q} 1,2}$ & $-26 \mathrm{~V} / 51 \mathrm{~V}$ \\
nominal torque $T$ & $8 \mathrm{~N} \mathrm{~m}$ \\
nominal speed $n$ & $3000 \mathrm{~min}^{-1}$ \\
\hline
\end{tabular}

\section{B. Effect of Inter-Turn Faults}

An inter-turn fault in the stator winding with the fault resistance $R_{\mathrm{F}}$ causes a circulating fault current $I_{\mathrm{F}}$, which generates the local heat $P_{\mathrm{F}}$ :

$$
P_{\mathrm{F}}=I_{\mathrm{F}}^{2} \cdot R_{\mathrm{F}}
$$

Additionally, the inter-turn fault reduces the average electromagnetic torque $\bar{T}$ and causes a distinct second harmonic ${ }^{2} T$. Since the generated heat $P_{\mathrm{F}}$ is neglectable compared to the rated machine power we do not further consider this torque reduction. The generated heat is determined by the number of shorted turns $w_{\mathrm{F}}$, the fault resistance $R_{\mathrm{F}}$ and the operating point, which is defined by the current vectors $i_{\mathrm{dq} 1}$ and $i_{\mathrm{dq} 2}$. and the speed $n$. An applied asymmetric operation also leads to a phase dependent heat generation. Considering all dependencies, the heat $P_{\mathrm{F}}$ can be expressed by the function $f$ with $z \in\{1, \ldots, 6\}$ :

$$
P_{\mathrm{F}}=f\left(i_{\mathrm{d} 1}, i_{\mathrm{q} 1}, i_{\mathrm{d} 2}, i_{\mathrm{q} 2}, n, w_{\mathrm{F}}, R_{\mathrm{F}}, \operatorname{Ph} z\right)
$$

The operation of a three-phase PMSM with an inter-turn fault causes second ${ }^{2} v_{\mathrm{dq}}$ and fourth ${ }^{4} v_{\mathrm{dq}}$ harmonics in the dq-voltages. This can be derived analytically [11]. The symmetric operation of a double three-phase machine equals the operation of an equivalent single three-phase machine. Therefore, we expect in total the same harmonic content in the dq-voltages of an inter-turn fault at symmetric operation. Asymmetric operation causes additional harmonics of the same order, caused by the asymmetric air-gap flux density. For the operation with a current controlled VSI, there are also harmonics in the dq-currents equivalent to the described voltage harmonics. However, the harmonic content of the dq-currents is neglectable for fast current controllers, especially with explicit mitigation of current harmonics [12]. Since the second harmonics ${ }^{2} v_{\text {dq }}$ are more distinct than the fourth harmonics ${ }^{4} v_{\mathrm{dq}}$ we focus on the fault detection and estimation based on the second harmonics of the dq-voltages. Fig. 2 shows the FEA simulation results for the second harmonics of the dq1 and dq2-voltages and the according heat generation for inter-turn faults in phase $\mathrm{Ph} 1$. For each scenario, the currents equal the nominal operation of Table I, the speed is $n=\left\{1500 \mathrm{~min}^{-1}, 3000 \mathrm{~min}^{-1}\right\}$, the number of shorted turns is $w_{\mathrm{F}}=\{1,2\}$ and the fault resistance is $R_{\mathrm{F}}=\{40 \mathrm{~m} \Omega, \ldots, 200 \mathrm{~m} \Omega\}$. Fig. 2 shows linear correlations between the amplitudes ${ }^{2} \hat{v}_{\mathrm{dq} 1}$ and ${ }^{2} \hat{v}_{\mathrm{dq} 2}$ and the heat $P_{\mathrm{F}}$. This means, we can use the amplitudes of the harmonics to determine the severity of the fault.

\section{Thermal Requirement}

A local temperature rise is caused by the generated heat of the inter-turn fault in the stator winding. The fault propagates rapidly if no limitation of the temperature rise is performed [5]. To prevent a catastrophic failure, it is especially for safety critical applications essential that the PMSM is able to fulfil the current load cycle. We require that the maximum temperature at the fault location stays below the minimum 


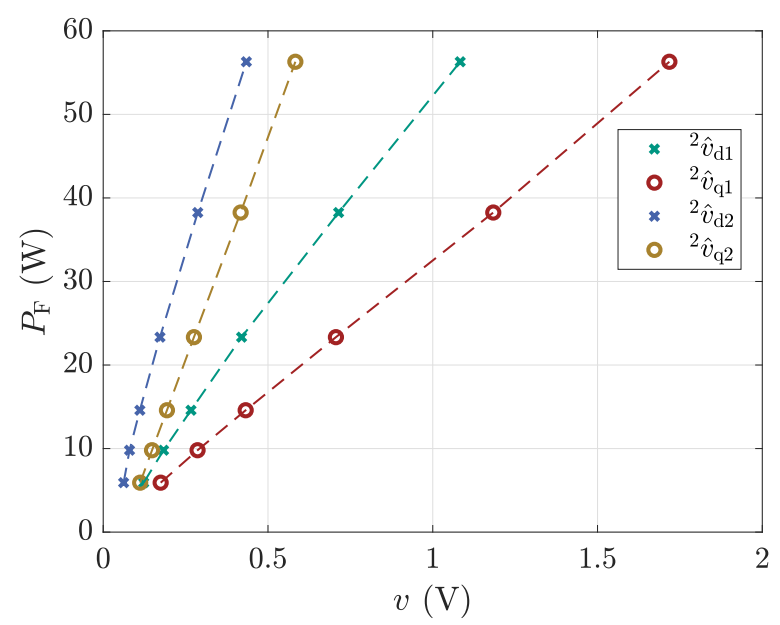

Fig. 2. Heat $P_{\mathrm{F}}$ over the amplitudes of the second harmonics ${ }^{2} \hat{v}_{\mathrm{dq} 1}$ and ${ }^{2} \hat{v}_{\mathrm{dq} 2}$ for different fault combinations at nominal current.

heat shock temperature, which is defined as $20 \mathrm{~K}$ above the thermal class rating. This thermal requirement prevents an instant breakup of the insulation and we assume that this allows the faulty machine to operate at least for the current load cycle. The temperature at the fault $T_{\mathrm{F}}$ depends on the machine geometry, cooling method, material properties, fault location and generated heat. We use a worst-case estimation and assume that the inter-turn fault occurs in the centre of the end windings of the machine. The thermal resistance between the end windings and the stator housing is much higher compared to the thermal resistance between the windings within the active material and the stator housing. Thus, the same local heat generation leads to an increased temperature rise in the end windings than in the active material. We performed a thermal 3D-FEA for the analysis of the worst case estimation. For the analysed PMSM, we assume a water jacket cooling with a temperature at the outer stator yoke of $T_{\mathrm{S} \text {,out }}=65^{\circ} \mathrm{C}$. Under healthy conditions, we assume that the temperature in the centre of the end windings, which equals the fault location, is $T_{\mathrm{F}}=100^{\circ} \mathrm{C}$. The thermal class rating of the conductor material is $200{ }^{\circ} \mathrm{C}$. The diameter of the conductor is $1.25 \mathrm{~mm}$ and the number of turns per slot is 20 . The analysis with the 3D-FEA shows that for the worstcase estimation the minimum heat shock temperature at the fault location of $T_{\mathrm{F}}=220^{\circ} \mathrm{C}$ is reached with a generated heat of $P_{\mathrm{F}}=15 \mathrm{~W}$. We assume a linear dependency between generated heat and temperature rise. This leads to the connection that every increase of $\Delta P_{\mathrm{F}}=5 \mathrm{~W}$ causes a temperature rise of $\Delta T_{\mathrm{F}}=40 \mathrm{~K}$.

\section{Asymmetric Operation}

Asymmetric operation of the double three-phase machine means that the current vectors $i_{\mathrm{dq} 1}$ and $i_{\mathrm{dq} 2}$ are different. If there is an inter-turn fault in one system, it is beneficial to operate the faulty and the healthy systems independently. The faulty system attenuates the arising fault while the healthy system compensates a possible torque reduction of the faulty system. The two surface plots in Fig. 3 show the average torque $\bar{T}$ of the presented double three-phase machine for the $i_{\mathrm{d} 1} / i_{\mathrm{q} 1}$-plane for two current vectors $i_{\mathrm{dq} 2}$. The maximum current of the machine is shown by the black circle. The first current vector of system dq2 is $i_{\mathrm{dq} 2}=0 \mathrm{~A}$, which represents the lower surface plot. The second current vector is $i_{\mathrm{d} 2}=-7.1 \mathrm{~A}$ and $i_{\mathrm{q} 2}=18.7 \mathrm{~A}$, which equals the MTPA point at the maximum current circle. Thus, the second current vector yields the upper surface plot. By way of comparison, the mesh plot shows the torque of the equivalent single three-phase machine, which is represented by $i_{\mathrm{dq} 1}=i_{\mathrm{dq} 2}$. With the double three-phase machine, we extend the operating area of the machine from a single 2D-plane to a 3D-space. If the faulty system operates solely in fieldweakening, the output torque of a single three-phase machine would be zero. In contrast, we are still able to produce an average torque of approximately $50 \%$ of the maximum torque with the double three-phase machine.

\section{Fault Tolerant Control}

The FTC scheme is shown in Fig. 4 and combines all relevant sub-functions. The torque $T_{1,2}^{*}$ provides the target value for both three-phase system, which equals half of the overall machine torque. During healthy operation, we calculate the target current vectors $i_{\mathrm{dq} 1}^{*}$ and $i_{\mathrm{dq} 2}^{*}$ with the MTPA approach. If the fault detection is active, the Fault Control Strategy (FCS) provides the input for the current controllers. We use current controllers with mitigation of current harmonics to provide the input signals for the VSIs. The phase voltages and phase currents are measured and then transformed into the dq-reference frame. These values serve as feedback for the current controllers and also input for the frequency analysis.

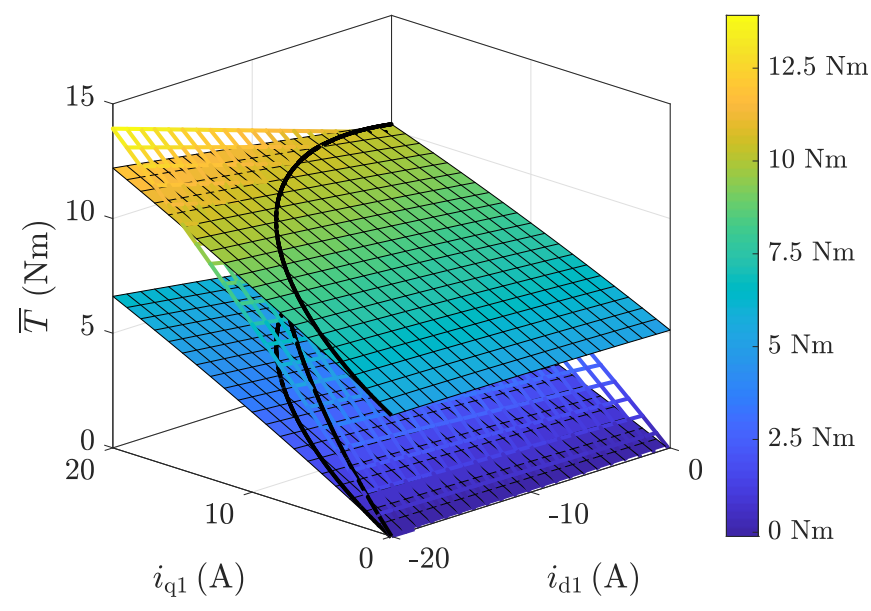

Fig. 3. Average torque $\bar{T}$ for the $i_{\mathrm{d} 1} / i_{\mathrm{q} 1}$-plane. For the upper surface plot the current vector $i_{\mathrm{dq} 2}$ is at the MTPA point with maximum current and for the lower surface plot $i_{\mathrm{dq} 2}$ equals zero. The mesh plot shows the single three-phase PMSM with $i_{\mathrm{dq} 1}=i_{\mathrm{dq} 2}$. 


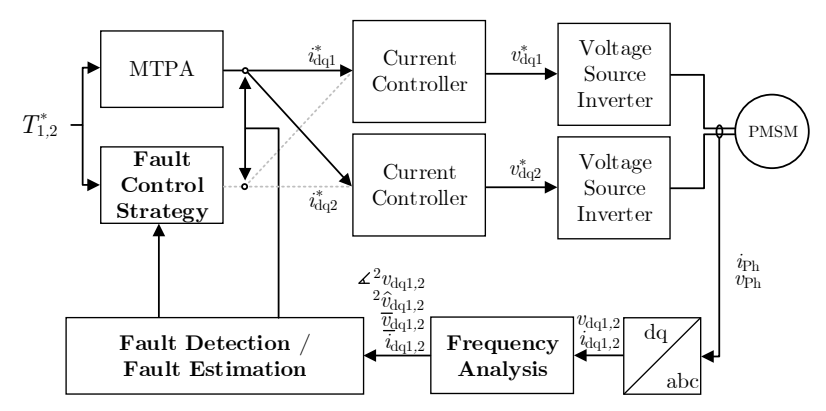

Fig. 4. Fault Tolerant Control (FTC) scheme for the double threephase machine, which includes the frequency analysis, fault detection and estimation and the Fault Control Strategy (FCS).

\section{A. Fault Control Strategy}

The fault detection switches the input for the current controller from MTPA to FCS if the estimated heat is greater than the threshold value of $15 \mathrm{~W}$. The amplitudes of the second harmonics are for the presented PMSM with a fault in phase $\mathrm{Ph} 1$ at nominal operation ${ }^{2} \hat{v}_{\mathrm{d} 1}=266 \mathrm{mV},{ }^{2} \hat{v}_{\mathrm{q} 1}=423 \mathrm{mV},{ }^{2} \hat{v}_{\mathrm{d} 2}=110 \mathrm{mV}$ and ${ }^{2} \hat{v}_{\mathrm{q} 2}=193 \mathrm{mV}$, which can be seen in Fig. 2. According to (1), the generated heat depends on fault current and, due to Ohm's law, also on the voltage across the shorted turns. Therefore, we choose to lower the phase voltage to reduce the generated heat by adjusting the target currents $i_{\mathrm{dqF}}^{*}$ of the faulty system and maintaining constant speed. Fig. 5 shows the heat $P_{\mathrm{F}}$ of an inter-turn fault in phase $\mathrm{Ph} 1$ with $w_{\mathrm{F}}=1$ shorted turn and $R_{\mathrm{F}}=50 \mathrm{~m} \Omega$ for the $i_{\mathrm{d} 1} / i_{\mathrm{q} 1^{-}}$ plane at $3000 \mathrm{~min}^{-1}$. We get the minimum generated heat if the maximum current of the faulty system is used for field weakening. The generated heat increases if the distance to the point of maximum field-weakening in the $i_{\mathrm{d} 1} / i_{\mathrm{q} 1}$-plane increases. For the exemplary inter-turn fault, the difference

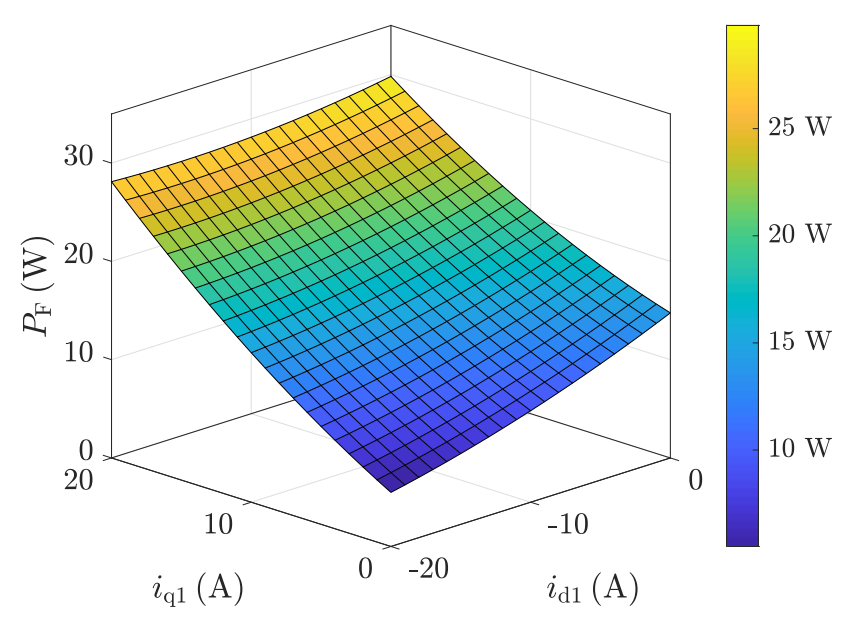

Fig. 5. Generated heat for the $i_{\mathrm{d} 1} / i_{\mathrm{q} 1}$-plane with an inter-turn fault in phase $\mathrm{Ph} 1$ with $w_{\mathrm{F}}=1$ and $R_{\mathrm{F}}=50 \mathrm{~m} \Omega$. System dq 2 operates at the nominal operating point and the speed is $3000 \mathrm{~min}^{-1}$.

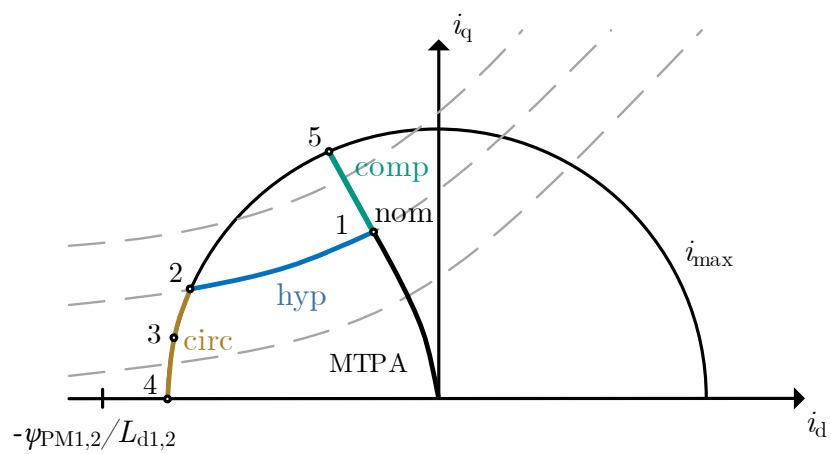

Fig. 6. Control Strategy for the double three-phase machine with the machine parameters $\left|-\psi_{\mathrm{PM} 1,2} / L_{\mathrm{d} 1,2}\right|>i_{\max }$.

between maximum and minimum heat is $\Delta P_{\mathrm{F}}=24.3 \mathrm{~W}$, which equals $\Delta T_{\mathrm{F}}=194^{\circ} \mathrm{C}$. The advantage of the double three-phase machine is that we can now use the healthy system to compensate a torque reduction of the faulty system. The resulting control strategy is shown in Fig. 6. During healthy operation, the starting point is defined for both systems by the nominal MTPA point nom1. If the estimated heat of an inter-turn fault exceeds the threshold value, the current vector $i_{\mathrm{dqF}}$ moves towards the point of maximum field weakening until the thermal requirement is fulfilled. Therefore, the current $i_{\mathrm{dF}}$ of the faulty system is reduced by a time-discrete PI-controller. The heat controller is shown in Fig. 7. The maximum heat $P_{\mathrm{F}, \max }^{*}$ is predefined by the thermal requirement. The heat $P_{\mathrm{F}, \mathrm{SVM}}$ is calculated by the fault estimation. We use the analytical model presented in [13] to tune the parameters $k_{\mathrm{I}}$ and $k_{\mathrm{P}}$ of the discrete PIcontroller with the sample time $T_{\mathrm{S}}$. It is essential to use the sample and hold block at the end of the heat controller with a pulse frequency equal to the fundamental electric frequency. This allows a steady-state operation to calculate the average and harmonic values for the heat estimation. Without the sample and hold block, the transient behaviour of the machine would lead to an incorrect estimation of the heat. At first, the operating point moves along the constant torque hyperbola hyp towards the point hyp2. We use a lookup table for the FTC scheme, which is generated by FEA simulations, to determine $i_{\mathrm{qF}}^{*}$ out of $i_{\mathrm{dF}}^{*}$ and $T^{*}$. If the current vector $i_{\mathrm{dqF}}$ reaches the point hyp2, the FCS switches to the circle of maximum current circ until the point circ 4 is

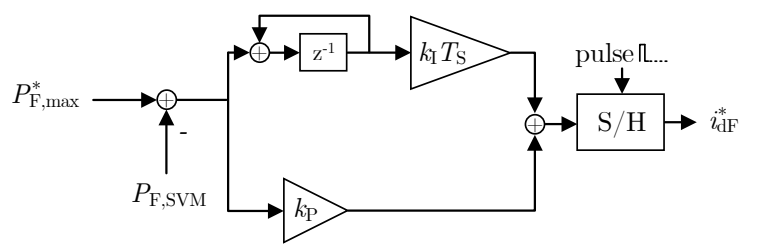

Fig. 7. Heat controller with the output $i_{\mathrm{dF}}^{*}$. 
reached. The healthy system begins to compensate the torque reduction of the faulty system when the current vector $i_{\mathrm{dqF}}$ switches to the maximum current circle. The current vector $i_{\mathrm{dqH}}$ starts moving along the MTPA curve comp towards the point comp5. The current vector of the healthy system can compensate the torque reduction until $i_{\mathrm{dqF}}$ reaches $\operatorname{circ} 3$.

\section{B. Fault Detection and Estimation}

There are various methods for the detection of inter-turn faults, from model based to data based approaches. The fault detection is implemented in combination with the fault estimation. We detect a fault if the estimated heat is greater than the predefined limit. For the fault estimation, we use a novel data based approach, which directly estimates the generated heat by the inter-turn fault. Due to the multidimensional and nonlinear dependencies of the generated heat, a supervised regression learner is used. We require a high efficiency and robustness of the fault estimation. Thus, we use a Support Vector Machine (SVM) with a quadratic Kernel function [14]. The classification of the faulty phase is based on the phase of the second harmonics of the voltages. We obtain the best results for the fault estimation if we use independent SVMs for each phase. To reduce the complexity of the approach, we now focus on an inter-turn fault in phase $\mathrm{Ph} 1$. The training data for the supervised learning are generated with the presented FEA model. For the inter-turn fault, we varied the number of shorted turns and the fault resistance. For the operating points, we varied the current vectors $i_{\mathrm{dq} 1}$ and $i_{\mathrm{dq} 2}$. The rotor speed is at constant $3000 \mathrm{~min}^{-1}$. Every training scenario includes the voltage harmonics ${ }^{2} \hat{v}_{\mathrm{dq} 1,2}$, the average voltages $\bar{v}_{\mathrm{dq} 1,2}$, the average currents $\bar{i}_{\mathrm{dq} 1,2}$ and the heat $P_{\mathrm{F}}$. MATLAB ${ }^{\circledR}$ is used to train the SVM with the gathered data. The training process takes less than 8 seconds for the 864 combinations. With a five-fold cross-validation, we get a Root Mean Square Error (RMSE) for the training data set of $\mathrm{RMSE}=3.5$. The new values can be predicted with the SVM regression formula [15]:

$$
P_{\mathrm{F}, \mathrm{SVM}}(\boldsymbol{x})=\sum_{n=1}^{N_{\mathrm{o}}}\left(\boldsymbol{\alpha}_{\boldsymbol{n}}-\boldsymbol{\alpha}_{\boldsymbol{n}}{ }^{*}\right) G\left(\boldsymbol{x}_{\boldsymbol{n}}, \boldsymbol{x}\right)+b
$$

Therein $\boldsymbol{x}$ denotes the input vector for the regression, $\boldsymbol{x}_{\boldsymbol{n}}$ denotes the multivariate set of $N_{\mathrm{o}}$ observations, $\boldsymbol{\alpha}_{\boldsymbol{n}}$ and $\boldsymbol{\alpha}_{\boldsymbol{n}}{ }^{*}$ denote nonnegative multipliers for every observation $x_{n}, G$ denotes the Kernel function and $b$ denotes the offset term. The input vector $\boldsymbol{x}$ includes:

$\boldsymbol{x}=\left[{ }^{2} \hat{v}_{\mathrm{d} 1} ;{ }^{2} \hat{v}_{\mathrm{q} 1} ;{ }^{2} \hat{v}_{\mathrm{d} 2} ;{ }^{2} \hat{v}_{\mathrm{q} 2} ; \bar{v}_{\mathrm{d} 1} ; \bar{v}_{\mathrm{q} 1} ; \bar{v}_{\mathrm{d} 2} ; \bar{v}_{\mathrm{q} 2} ; \bar{i}_{\mathrm{d} 1} ; \bar{i}_{\mathrm{q} 1} ; \bar{i}_{\mathrm{d} 2} ; \bar{i}_{\mathrm{q} 2}\right]$

The second order polynomial Kernel function $G$ is given by:

$$
G\left(\boldsymbol{x}_{\boldsymbol{n}}, \boldsymbol{x}\right)=\left(1+\boldsymbol{x}_{\boldsymbol{n}}{ }^{\prime} \boldsymbol{x}\right)^{2}
$$

\section{Frequency Analysis}

We use the frequency analysis to calculate, for both systems, the phase angles $\measuredangle^{2} v_{\mathrm{dq} 1,2}$ and the amplitudes ${ }^{2} \hat{v}_{\mathrm{dq} 1,2}$ of the second harmonics and the average values $\bar{i}_{\mathrm{dq} 1,2}, \bar{v}_{\mathrm{dq} 1,2}$.
The Goertzel algorithm is used for the calculation, due to the increased efficiency for individual frequencies compared to the N-point Discrete Fourier Transformation [16].

\section{Simulation Results}

The simulation results are generated with the presented FEA model. We simulated a specific fault scenario and determined the fault tolerant capabilities.

\section{A. Fault Scenario}

For the simulation of the fault scenario, we choose a constant inter-turn fault in phase $\mathrm{Ph} 1$, which is explicitly not part of the training data. The inter-turn fault is defined by $w_{\mathrm{F}}=1$ and $R_{\mathrm{F}}=40 \mathrm{~m} \Omega$. We use for the FTC $k_{\mathrm{I}}=30$ and $k_{\mathrm{P}}=0.2$ with the sample time $T_{\mathrm{S}}=200 \mu$ s as parameters for the heat controller. Fig. 8 shows the resulting currents $i_{\mathrm{d} 1}$, $i_{\mathrm{q} 1}, i_{\mathrm{d} 2}$ and $i_{\mathrm{q} 2}$ over time $t$. The machine operates initially at the nominal operating point, which is defined by $i_{\mathrm{d} 1,2}=-4 \mathrm{~A}$, $i_{\mathrm{q} 1,2}=14.3 \mathrm{~A}$ and $n=3000 \mathrm{~min}^{-1}$. A fault is detected since $P_{F} \geq 15 \mathrm{~W}$. Thus, the target values $i_{\mathrm{dq} 1}^{*}$ and $i_{\mathrm{dq} 2}^{*}$ for the current controllers are determined by the FCS. The heat controller decreases the current $i_{\mathrm{d} 1}$ of the faulty system every $10 \mathrm{~ms}$ since the electric frequency is $100 \mathrm{~Hz}$. For the first four steps, the current $i_{\mathrm{q} 1}$ is determined by the torque hyperbola and the current vector $i_{\mathrm{dq} 2}$ stays at the point nom1. The following four steps, the current $i_{\mathrm{q} 1}$ is determined by the maximum current circle and the current vector $i_{\mathrm{dq} 2}$ moves along the MTPA curve towards the point comp5. The fault tolerant operating point is reached after eight periods and is defined by $i_{\mathrm{d} 1}=-18.2 \mathrm{~A}, i_{\mathrm{q} 1}=8.3 \mathrm{~A}, i_{\mathrm{d} 2}=-6.0 \mathrm{~A}$ and $i_{\mathrm{q} 2}=17.4$ A. Fig. 9 shows the voltages $v_{\mathrm{d} 1}, v_{\mathrm{q} 1}, v_{\mathrm{d} 2}$ and $v_{\mathrm{q} 2}$ over time $t$. It can be clearly seen that the average voltages $\bar{v}_{\mathrm{d} 1}$ and $\bar{v}_{\mathrm{q} 1}$ decrease continuously to lower the heat $P_{\mathrm{F}}$. The voltage spikes are caused by the transient behaviour of the machine at each change of the target currents. Fig. 10 shows the sample and hold amplitudes of the second harmonics

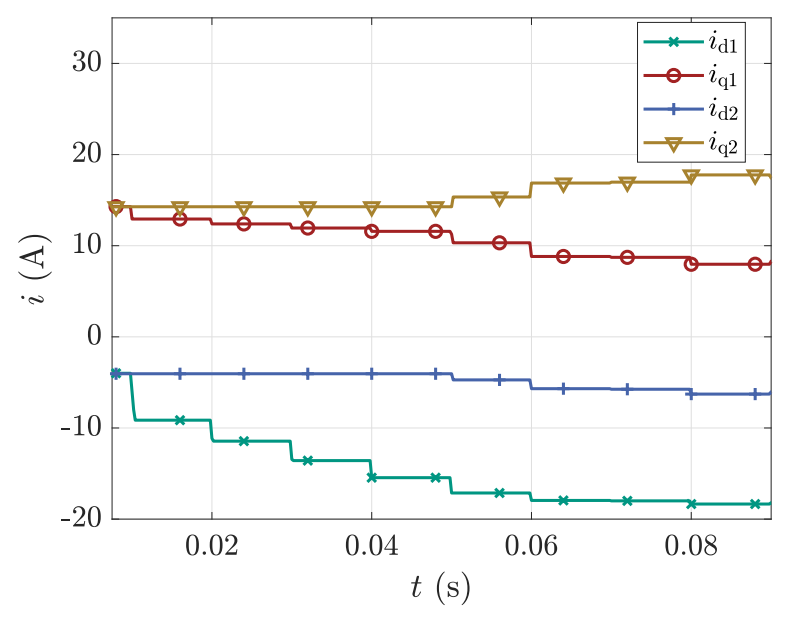

Fig. 8. Currents $i_{\mathrm{d} 1}, i_{\mathrm{q} 1}, i_{\mathrm{q} 2}$ and $i_{\mathrm{d} 2}$ over time $t$. 
${ }^{2} \hat{v}_{\mathrm{dq} 1, \mathrm{SH}}$ and ${ }^{2} \hat{v}_{\mathrm{dq} 2, \mathrm{SH}}$ over time $t$. The amplitudes of system $\mathrm{dq} 1$ are initially increased compared to the amplitudes of system dq2 since the inter-turn fault is located in phase Ph1. The amplitudes of the second harmonics of the equivalent single-three phase machine would decrease continuously because there is no asymmetric operation. For the double three-phase machine, the amplitudes of the second harmonics increase, which is caused by the asymmetric operation. Fig. 11 shows the torque $T_{6 \mathrm{ph}}$ of the analysed double threephase machine and for comparison the torque $T_{3 \mathrm{ph}}$ of the equivalent single three-phase machine. The proposed FTC scheme is able for the double three-phase machine to keep the average torque constant, while reducing the generated heat to the allowed minimum. The second harmonic of the torque slightly increases, due to the asymmetric operation. The proposed scheme for the single three-phase machine is not able to keep the torque constant, which results in a torque reduction of $28 \%$. Fig. 12 finally shows the estimated

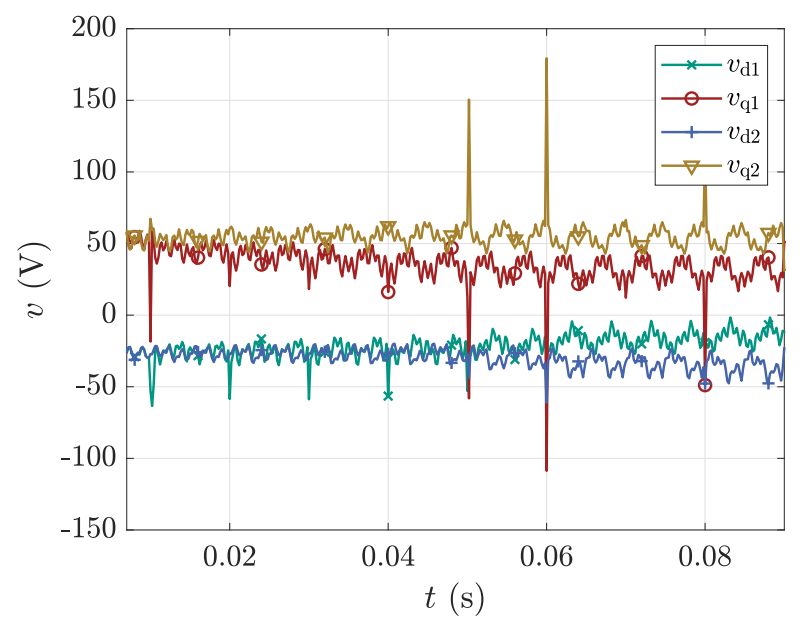

Fig. 9. Voltages $v_{\mathrm{d} 1}, v_{\mathrm{q} 1}, v_{\mathrm{q} 2}$ and $v_{\mathrm{d} 2}$ over time $t$.

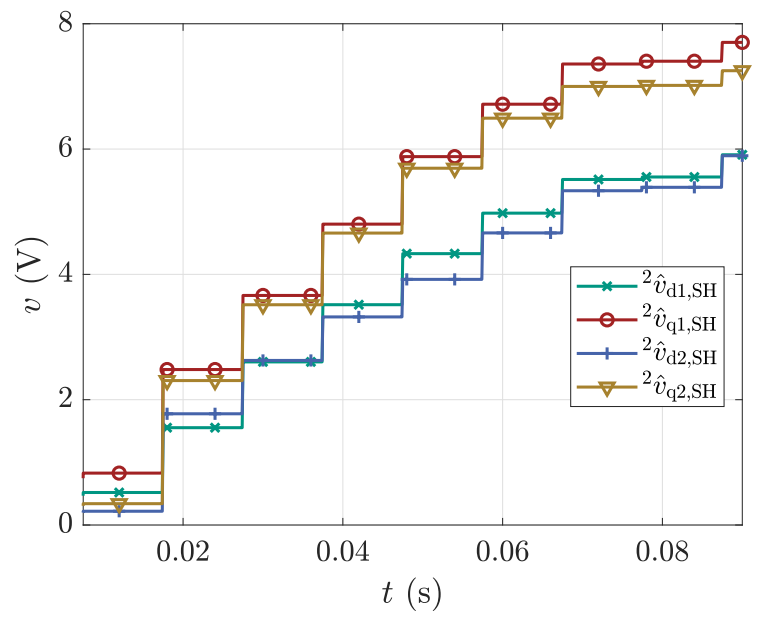

Fig. 10. Sample and hold amplitudes of the second harmonics ${ }^{2} \hat{v}_{\mathrm{dq} 1, \mathrm{SH}}$, ${ }^{2} \hat{v}_{\mathrm{dq} 2, \mathrm{SH}}$ over time $t$.

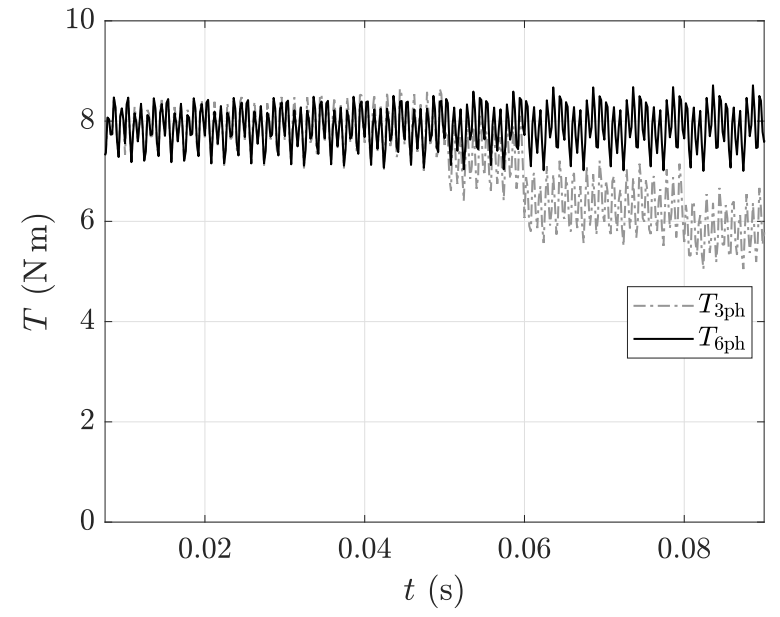

Fig. 11. Torque $T_{6 \mathrm{ph}}$ of the double three-phase machine and torque $T_{3 \mathrm{ph}}$ of the equivalent single three-phase machine over time $t$.

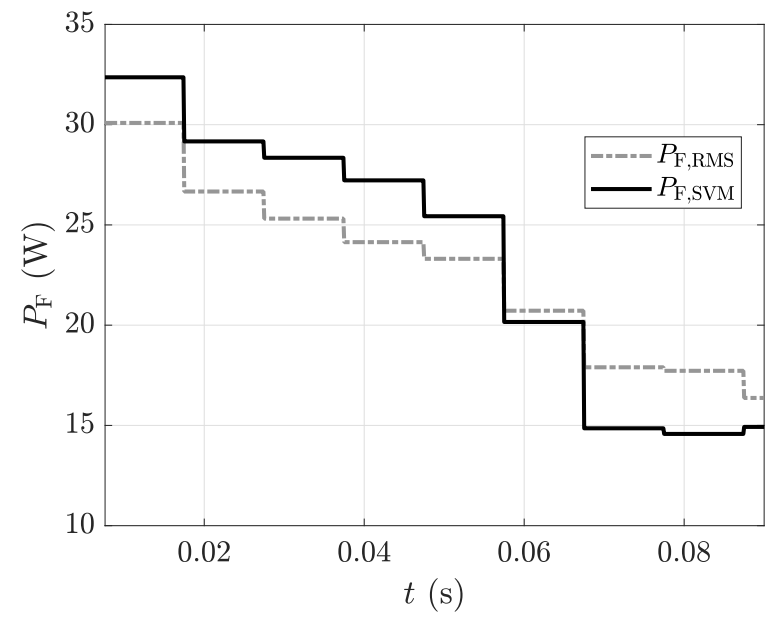

Fig. 12. Estimated heat by the SVM $P_{\mathrm{F}, \mathrm{SVM}}$ and calculated heat by the RMS value of the fault current $P_{\mathrm{F}, \mathrm{RMS}}$ over time $t$.

heat $P_{\mathrm{F}, \mathrm{SVM}}$ by the SVM and the calculated heat $P_{\mathrm{F}, \mathrm{RMS}}$ by the RMS value of the fault current according to (1). The SVM overestimates the generated heat for the first five steps. The final value of the fault tolerant operating point is underestimated by $1.3 \mathrm{~W}$. This equals an underestimation of the temperature at the fault of $\Delta T_{\mathrm{F}}=10.4 \mathrm{~K}$. The calculated heat is reduced in total by $\Delta P_{\mathrm{F}}=13.5 \mathrm{~W}$, which equals a temperature reduction of $\Delta T_{\mathrm{F}}=108 \mathrm{~K}$.

\section{B. Fault Tolerant Capabilities}

There are two values which characterize the fault tolerant capabilities of a specific machine. The first value describes the maximum heat reduction which the FTC scheme can achieve at nominal speed without reducing the torque. For the second characteristic value, we look for the maximum heat reduction, which can be realized with reduced torque at nominal speed. The double three-phase machine can 
still operate at nominal torque if the current vector $i_{\mathrm{dq} 1}$ is shifted from nom $1 \rightarrow \operatorname{circ} 3$ and $i_{\mathrm{dq} 2}$ is shifted from nom $1 \rightarrow$ comp5. Therefore, the first characteristic value for the compensation is $\Delta P_{\mathrm{F}}=13.9 \mathrm{~W}$. For the equivalent threephase machine, we can only shift the current vector from nom $1 \rightarrow$ hyp 2 to operate at nominal torque. This results in a reduced heat reduction of $\Delta P_{\mathrm{F}}=8 \mathrm{~W}$. For the second characteristic value of the double three-phase machine, the current vector $i_{\mathrm{dq} 1}$ is shifted from nom $1 \rightarrow \operatorname{circ} 4$ and $i_{\mathrm{dq} 2}$ is shifted again from nom $1 \rightarrow$ comp5. This allows a maximum heat reduction of $\Delta P_{\mathrm{F}}=44.3 \mathrm{~W}$ and an average torque of still $\bar{T}=5.4 \mathrm{Nm}$. For the equivalent three-phase machine, the maximum heat reduction is achieved if the current vector is shifted from nom $1 \rightarrow$ circ4. This leads to a heat reduction of $\Delta P_{\mathrm{F}}=30.1 \mathrm{~W}$ and an approximately zero output torque. The magnetic coupling among both threephase systems leads to an increased heat reduction for the double three-phase machine at the asymmetric operation, which causes the difference in heat reduction for the second characteristic value. Thus, the fault tolerant capabilities can be significantly improved by operating the machine with two independent three-phase inverters. The first characteristic value is improved by $74 \%$ at the same output torque. The second one is improved by $47 \%$ with a difference in the output torque of $\Delta \bar{T}=5.3 \mathrm{Nm}$.

\section{SUMMARY}

In this paper, we present a FTC scheme for double threephase PMSMs which limits the generated heat of an inter-turn fault to a maximum allowable value. The basic assumption is that the limited heat at the fault also limits the propagation of the fault since the temperature is reduced. We use an SVM regression to estimate the generated heat of the inter-turn fault. If the estimated heat is greater than the threshold value, the FCS shifts the current vector of the faulty system along the constant torque hyperbola. If the thermal requirement can still not be fulfilled, the current vector of the faulty system moves along the maximum current circle towards to point of maximum field-weakening. The advantage of the double three-phase machine is that now the healthy system can compensate the torque reduction of the faulty system to extend the fault tolerant capability. The output torque is still at $66 \%$ of the nominal torque if the faulty system operates at the point of maximum field-weakening and the healthy system operates at the MTPA point with maximum current. The transient voltages, which arise at every step of the target currents, limit the speed of the fault estimation. Therefore, we use one fundamental electric period to estimate the generated heat and subsequently adapt the operating point. We are able to prove the concept of the presented FTC scheme for double three-phase machines with FEA simulation results. We currently build a test bench to validate the simulation results with measurement data.

\section{REFERENCES}

[1] C. Zoeller, M. A. Vogelsberger, T. M. Wolbank, and H. Ertl, "Impact of $\mathrm{SiC}$ semiconductors switching transition speed on insulation health state monitoring of traction machines," IET Power Electronics, vol. 9, no. 15 , pp. 2769-2775, Dec 2016.

[2] "Report of large motor reliability survey of industrial and commercial installations, part i," IEEE Transactions on Industry Applications, vol. IA-21, no. 4, pp. 853-864, 1985.

[3] C. Lai, A. Balamurali, V. Bousaba et al., "Analysis of stator winding inter-turn short-circuit fault in interior and surface mounted permanent magnet traction machines," in 2014 IEEE Transportation Electrification Conference and Expo (ITEC). IEEE, Jun 2014.

[4] B.-G. Gu, "Study of IPMSM interturn faults part II: Online fault parameter estimation," IEEE Transactions on Power Electronics, vol. 31 , no. 10, pp. 7214-7223, Oct 2016.

[5] V. Lešić, M. Vašak, N. Perić et al., "Fault-tolerant control of a wind turbine with generator stator inter-turn faults," Automatika, vol. 54 no. 1, pp. 89-102, Jan 2013.

[6] J. G. Cintron-Rivera, S. N. Foster, and E. G. Strangas, "Mitigation of turn-to-turn faults in fault tolerant permanent magnet synchronous motors," IEEE Transactions on Energy Conversion, vol. 30, no. 2, pp. 465-475, Jun 2015

[7] S. Foitzik and M. Doppelbauer, "Fault tolerant control of 3ph pmsm with inter-turn faults," in The 10th International Conference on Power Electronics, Machines and Drives (PEMD). IEEE, 2020, unpublished.

[8] E. Levi, "Multiphase electric machines for variable-speed applications," IEEE Transactions on Industrial Electronics, vol. 55, no. 5, pp. 1893 1909, May 2008.

[9] T. Miller and M. McGilp, "Analysis of multi-phase permanent-magnet synchronous machines," in 2009 International Conference on Electrical Machines and Systems. IEEE, Nov 2009.

[10] S. Foitzik and M. Doppelbauer, "Analytical model of a six-phase PMSM for the simulation of stator winding faults on turn level," in 2019 IEEE International Electric Machines \& Drives Conference (IEMDC). IEEE, May 2019.

[11] T. Boileau, N. Leboeuf, B. Nahid-Mobarakeh et al., "Stator winding inter-turn fault detection using control voltages demodulation," in IEEE Transportation Electrification Conference and Expo (ITEC), 2012. Piscataway, NJ: IEEE, 2012, pp. 1-6.

[12] J. Richter and M. Doppelbauer, "Control and mitigation of current harmonics in inverter-fed permanent magnet synchronous machines with non-linear magnetics," IET Power Electronics, vol. 9, no. 10, pp. 2019-2026, Aug 2016.

[13] S. Foitzik and M. Doppelbauer, "Simulation of stator winding faults with an analytical model of a PMSM," in 2018 IEEE International Conference on Power Electronics, Drives and Energy Systems (PEDES). IEEE, Dec 2018.

[14] G. A. Susto, A. Schirru, S. Pampuri et al., "Machine learning for predictive maintenance: A multiple classifier approach," IEEE Transactions on Industrial Informatics, vol. 11, no. 3, pp. 812-820, Jun 2015.

[15] J. Friedman, T. Hastie, and R. Tibshirani, The elements of statistical learning. Springer series in statistics New York, 2001, vol. 1.

[16] J. G. Ferreira and A. Warzecha, "An application of machine learning approach to fault detection of a synchronous machine," in 2017 International Symposium on Electrical Machines (SME). Piscataway, NJ: IEEE, 2017, pp. 1-6.

Simon Foitzik was born in Ellwangen, Germany. He received his B.Sc. and M.Sc. degrees in electrical engineering from the Karlsruhe Institute of Technology (KIT), Karlsruhe, Germany, in 2015 and 2017, respectively. $\mathrm{He}$ is currently working towards his Ph.D. degree at the KIT, Institute of Electrical Engineering (ETI) in the laboratory of Hybrid Electric Vehicles (HEV). His research interests include the fault tolerant control of electrical machines.

Martin Doppelbauer was born in Altenhundem, Germany. He received the Dipl.-Ing. and Dr.-Ing. degrees in electrical engineering from the University of Dortmund, Dortmund, Germany, in 1990 and 1995, respectively. He has worked with the companies Danfoss Bauer, Esslingen, and SEW Eurodrive, Bruchsal, Germany, as a Senior Manager for electric motor development. He has been holding the Professorship for Hybrid Electric Vehicles (HEV) at the Karlsruhe Institute of Technology (KIT) since 2011. 